\title{
Dermoscopy of Pigmented Vulvar Basal Cell Carcinoma
}

\author{
Carolina Bertaina ${ }^{1}$, Gabriel Salerni ${ }^{1,2}$, Melisa Celoria ${ }^{1}$, Silvina Lombardo ${ }^{1}$, \\ Mario Gorosito ${ }^{3}$, Ana Molteni ${ }^{1}$, Ramón Fernández-Bussy ${ }^{1}$
}

\author{
1 Hospital Provincial del Centenario de Rosario, Argentina; Faculty of Medicine, Universidad Nacional de Rosario, Argentina \\ 2 Diagnóstico Médico Oroño, Rosario, Argentina \\ 3 Pathology Department, Universidad Nacional de Rosario, Argentina
}

Key words: basal cell carcinoma, dermoscopy, skin cancer, imaging techniques

Citation: Bertaina C, Salerni G, Celoria M, Lombardo S, Gorosito M, Molteni A, Fernández-Bussy R. Dermoscopy of pigmented vulvar basal cell carcinoma. Dermatol Pract Concept. 2019;9(3):239-240. DOI: https://doi.org/10.5826/dpc.0903a20

Accepted: January 22, 2019; Published: July 31, 2019

Copyright: $@ 2019$ Bertaina et al. This is an open-access article distributed under the terms of the Creative Commons Attribution License, which permits unrestricted use, distribution, and reproduction in any medium, provided the original author and source are credited.

Funding: None.

Competing interests: The authors have no conflicts of interest to disclose.

Authorship: All authors have contributed significantly to this publication.

Corresponding author: Gabriel Salerni, MD, Bv. Oroño 1441, CP 2000, Rosario, Argentina. Email: gabrielsalerni@hotmail.com

\section{Introduction}

Basal cell carcinoma (BCC) is the most frequent nonmelanoma skin neoplasm in Caucasians. BCC is mostly located in photo-exposed areas; however, it can be observed in nonexposed areas such as armpits, genital and perianal regions, palms and soles, and in oral mucosa. Vulvar BCC is infrequent, being about $1 \%$ of all BCCs and $2 \%-4 \%$ of vulvar neoplasms. The dermoscopic aspect of BCC in this location has been described in very few cases.

\section{Case Presentation}

A 73-year-old woman presented with a 5-month history of a gradually enlarging tumor with gray-black coloration in the right upper labia majora, $0.5 \times 0.5 \mathrm{~mm}$, rounded, with raised edges and central ulceration (Figure 1A). The lesion was indurated on palpation; inguinal adenopathies were not identified. Dermoscopy showed the presence of irregularly shaped blue-black clods and structureless blueish areas. Structureless red-pink areas were also observed. The lesion was surrounded by a whitish halo; no specific vascular pat- tern was identified (Figure 1B). Full excisional biopsy was performed and histology evaluation reported the diagnosis of BCC (Figure 2).

\section{Conclusions}

Although it is believed that ultraviolet radiation is the main risk factor for the development of BCC, physiopathogenesis behind the occurrence in sun-protected areas is not yet defined. It has been suggested that advanced age, local trauma, chronic inflammation, and radiotherapy can contribute to the appearance in this area, as well as risk factors commonly associated with BCC including artificial ultraviolet radiation, exposure to arsenic, immunodeficiency, and genetic mutations.

Vulvar BCC occurs more frequently in postmenopausal women, aged between 50 and 70 years. Labia majora mucosa is the usual location in most cases. Clinical findings are diverse and do not always suggest BCC. Vulvar BCC usually presents as a single lesion, superficial, exophytic, ulcerated, infiltrating or nodular; only $3 \%$ of the lesions are pigmented. 
They are usually diagnosed in advanced stages, since most are asymptomatic and slow-growing; eventually the presence of itching, burning, or bleeding may raise concern.

The dermoscopic characteristics are usually the same as those observed in cutaneous BCC [1]; blue-gray ovoid nests and arborizing vessels have been reported in pigmented vulvar BCC [2].

Vulvar BCC is usually locally aggressive, so it requires complete excision with 4-mm margins to minimize recurrences; Mohs surgery is recommended. Prognosis is usually favorable, since it rarely metastasizes, but the risk of recurrence demands strict periodic monitoring.

In this case, dermoscopy was shown to be a helpful tool for the identification of vulvar pigmented BCC, improving diagnostic accuracy and allowing a correct therapeutic approach.

\section{References}

1. de Giorgi V, Massi D, Mannone F, et al. Dermoscopy in vulvar basal cell carcinoma. Arch Dermatol. 2007;143(3):426427.

2. Dobrosavljevic Vukojevic D, Djurisic I, Lukic S, Kastratovic-Kotlica B, Vukicevic J. Dermatoscopy in vulvar basal cell carcinoma. J Eur Acad Dermatol Venereol. 2017;31(4):e180-e181.

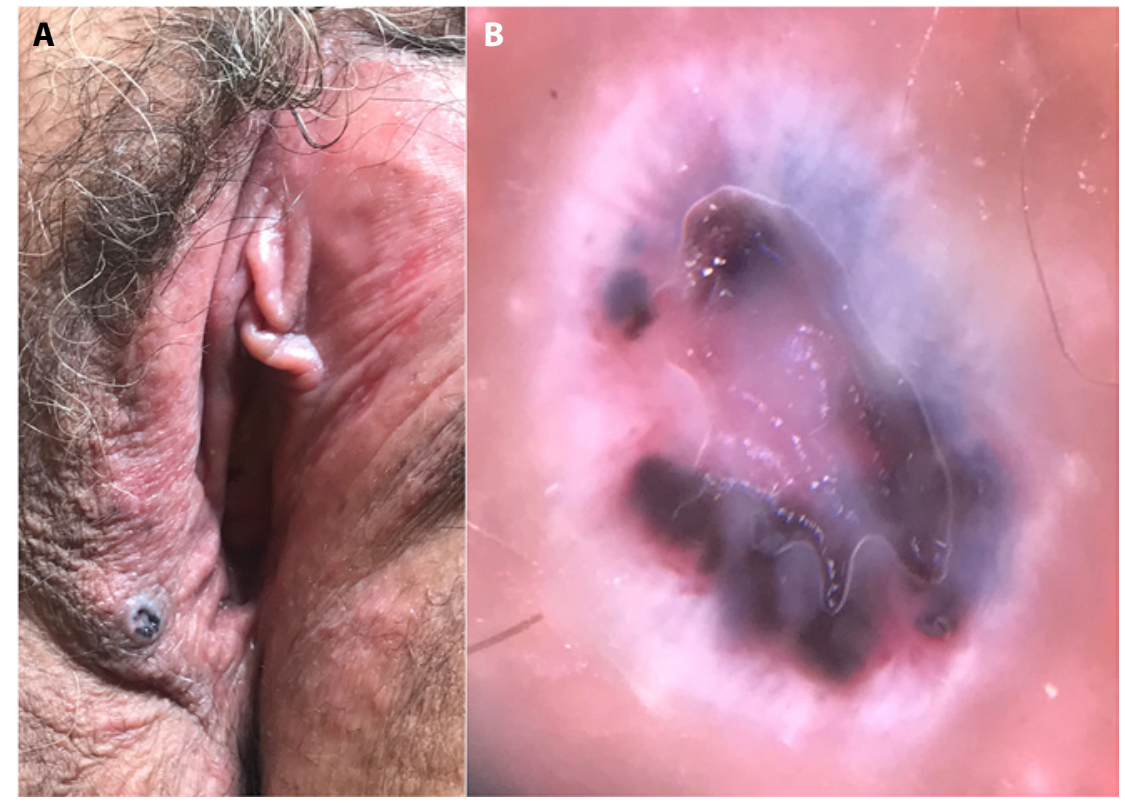

Figure 1. (A) Clinical aspect of the lesion. (B) Dermoscopy image: Irregularly shaped blueblack clods and structureless bluish and red-pink areas were observed. The lesion was surrounded by a whitish halo. [Copyright: @2019 Bertaina et al.]

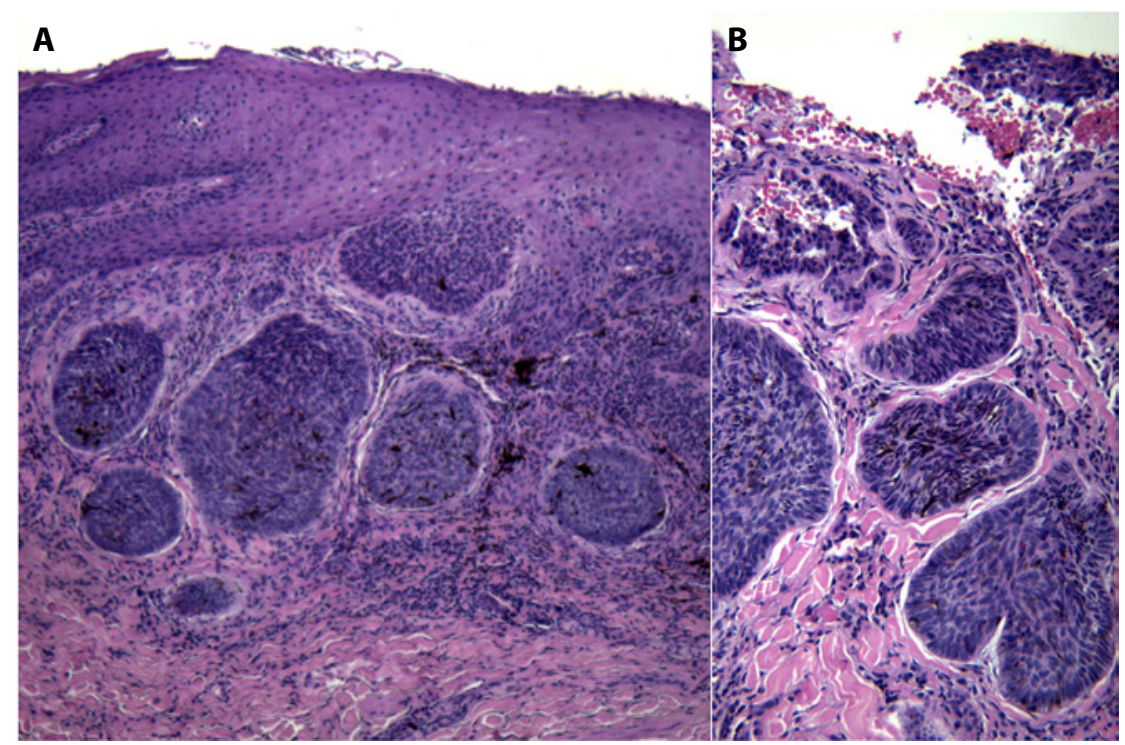

Figure 2. Neoplastic proliferation with basaloid pattern, with neoplastic nodules in the dermis and in contact with the surface epithelium. (A) The stroma exhibits leukocytic infiltrate and numerous melanophages $(\mathrm{H} \& \mathrm{E}, \times 20)$. (B) Ulceration and presence of basaloid nodules and infiltrating cords were observed $(\mathrm{H} \& \mathrm{E}, \times 40)$. H\&E = hematoxylin and eosin. [Copyright: (C2019 Bertaina et al.] 